\title{
Theory of Mind: Autism and Typical Developmental
}

\author{
Frolli A $^{1^{*}}$, I La Penna ${ }^{2}$, Cavallaro A $^{1},{ }^{2}$ and Ricci MC $^{2}$ \\ ${ }^{1}$ Disability Research Centre of Università degli Studi Internazionali di Roma, Italy \\ ${ }^{2}$ FINDS - Fondazione Italiana Neuroscienze e Disordini dello Sviluppo, Italy
}

Submission: December 06, 2019; Published: December 17, 2019

*Corresponding author: Frolli Alessandro, Disability Research Centre of Università degli Studi Internazionali di Roma, Via Cristoforo Colombo, 200, Roma, XiaoLin Tong, Guang'anmen Hospital, Academy of Chinese Medical Sciences, Beijing, China

\begin{abstract}
The ability to mentalize that is to understand and manipulate other people's behavior in terms of their mental states, is a major factor in successful social interactions. Specific impairments of mentalizing in both developmental and acquired disorders suggest that this ability depends on a dedicated and circumscribed brain system. Functional imaging studies implicate medial prefrontal cortex and posterior superior temporal sulcus (STS) as components of this system. Mentalizing capacities are acquired in first attachment relationships, they are the basis of empathy (i.e the consciousness and sharing of other's mental states). The lack of mentalization is the consequence of the failure of parental reflective capacities and of dysfunctions of attachment and family relationships. Research evidenced that these conditions are correlated with the development of insecure attachment, psychiatric diseases (autism, personality disorders, eating disorders, depression), aggressive and antisocial behaviors.
\end{abstract}

Keywords: Theory of mind; Autism; Psychological developmental; Children; Metacognition; Mentalization Network

\section{Introduction}

The Theory of Mind (ToM) consists of the cognitive ability to be able to represent one's own and others' mental states, that are beliefs, desires, emotions, to explain and anticipate the implementation of parameters. It is a cognitive capacity innate in every human being, whose development is influenced by the cultural context and the intellectual abilities of the individual. The first function of the theory of mind is social: mentalization helps us to understand others' behavior, giving meaning to the actions we observe even if others don't explain them directly. In the field of communication, the theory of mind makes us the interlocutors able to grasp the implicit intentions that are at the base of a message. This understanding also leads to the possibility of predicting the behavior of the people we observe. For the child this is, perhaps, the most important function as it allows to create the expectations and verify them, as well as to adapt the behavior according to the interlocutor, by learning to be flexible. Premack and Woodruff [1] were the first to talk about Theory of Mind that is the ability to understand an individual's mental state starting from manifest behavior. At first, they observed this ability in chimpanzees who were able to predict a man's behavior in goaloriented situations. Thus, the Theory of Mind is a skill evolved in hominids in response to the social environment and to situations that arise, becoming increasingly heterogeneous in dissimilar contexts. Naturally, since this is an attitude, each individual will present a Theory of Mind more or less developed according to their cognitive resources and relational abilities. During the 1980s, the publication of the researches by Wimmer and Perner [2], Baron-Cohen and colleagues [3] and Perner and colleagues [4] gave rise to a rich line of studies on the development of ToM in the developmental age.

One of these, is the Theory of Theory (Gopnik and Wellman, [5]) according to which mental activity is based on knowledge that occurs empirically and the child acquires them during development by learning to discriminate real situations from hypothetical ones. In this way, a theory of the Theory of Mind is developed, and it allows him to infer mental representations and to construct his own representation of the world. Mental representations are called meta-representations. Other developmental psychologists who have conducted research on Theory of Theory are Perner [4]: they have applied their theories to children, considering them as little scientists who form and review their thinking about various domains. Children are born with the tendency to create naive or popular theories, that are representations organized on particular areas of reality, for example the knowledge that desires bring to 
intentions: a child can understand that another child wants to find his new game and therefore intends to look for it. Children use these explanatory theories to interpret the world, predict future events and explain past events just like scientists do. The most important scientific discovery in the development of ToM was that of Wimmer and Perner [2] on the task of false belief, that serves to verify the development of the meta-representational capacity in humans, or the development of a theory of mind. To solve this test the child must momentarily suspend his knowledge of reality, assume the perspective of the other and represent himself the content of his mind, that is a false belief with respect to reality, so as to correctly predict how the other will behave on the basis of own false belief. Having ToM means putting in place a process of meta-representation of mental states: the individual strives to infer the contents of the human mind, which are subjective and therefore opaque from a referential point of view. This meta-representation process can lead to more or less accurate explanations or predictions of behavior. This cognitivemeta-representational view is adopted by the Theory of Theory approach (Wellman, [6]), which proposes an analogy between the child dealing with the construction of the understanding and the explanation of the mind, and the scientist committed to elaborating a theoretical system. The ability to recognize that the other person has a belief that differs not only from his own, but also from the reality fact (false belief) opens the way to the understanding and awareness of the subjectivity of mental states, which allows to exit from the intellectual egocentrism and to intervene to influence mental states, modifying the course of actions (actions such as persuading, lying, etc.).

Bruner [7] will propose the term "comprehension", typical of narrative thought and of the work of interpretation that supports it, to "explanation", typical of the metarepresentational construct of ToM in the Theory of Theory approach. The Theory of Simulation explains the theory of mind by referring to the capacity of simulation, whose neural correlation is the system of mirror neurons. It would constitute the brain basis for understanding actions through simulation processes. This theory is based on its own cognitive mechanisms to attribute and predict the mental states of others; according to this view, the observer identifies himself with the other during the attribution and he imagines that is in the same situation as the observed. The process that leads to predicting the behavior of the other presupposes therefore to mentally simulate desires and beliefs that are supposed to match those of the individual with whom one interacts. The result is the elaboration of a decision made according to its own decisionmaking mechanisms that tries to predict the behavior of others. The subject makes an inference backwards that starts from the action observed in the other and reaches to hypothesize its objectives (Gallese \& Goldman, [8]). This approach is supported by Meltzoff's treatment, which explains the evolution of a theory of mind thanks to the model like me, based precisely on the imitation process (Meltzoff, [9]). In summary, this position would aim to derive human social cognition from the motor system (Jacob \& Jeannerod, [10]). A test in favor of this perspective can be represented by the result of a study (Fadiga et al., [11]) which demonstrated how observers are facilitated in the motor activation of the same muscle groups that is using the target agent, or the observed agent, during the action. The Modular Theory is linked to Fodor's theory of modular mind, according to which the human mind is made up of specialized modules, genetically determined and functioning independently.

For this there is a module in which the Theory of MindModule is processed, which gets useful information from the social environment. The ToM-Module is able to separate the relevant contextual information from the irrelevant information, thus increasing the probability of a correct inference of the mental states of others. The development of this ability would depend mainly on the neurological maturation of the brain structures involved, while the experience would determine its use. In the Baron-Cohen model the capacities of ToM would be the result of the functioning of an innate component of our cognitive system, that is the neurobiological maturation of a specific brain structure, a module, for the analysis of one's own and others' mental states (Baron -Cohen, Leslie and Frith [3]; Leslie [12]). A turning point in the socio-contextualist direction became evident with the work of two authors such as Elizabeth Meins and Peter Fonagy, with whom there were advantageous connections with the domain of affective development. The first proposed a conjugation between Vygotsky's theory and attachment theory, to formulate a new construct in the development of mentalization: maternal MindMindedness, defined as the propensity to treat one's child as an active subject, endowed with a mind, and to use in the interaction terms that relate appropriately to mental states. The most important fact that emerges from the first studies conducted by Meins $[13,14]$ concerns the ability of mothers of children with secure attachment to act as tutorial figures within the proximal development zone of the child, playing that important role of scaffolding to help him to give meaning to the task and carry it out in the progressive construction of intersubjectivity between the two partners. The placement of the Bowlby's concept of secure base (Bowlby, 1980) within the Vygotskij's concept of proximal development zone has provided an important building block in the construction of connection between cognitive and affective development, a conjunction that also emerges in ToM (Meins et al., [15]): children with secure attachment exceed the task of false belief in a much higher percentage than those with insecure attachment. Peter Fonagy defines the capacity for maternal containment as a metacognitive competence, which makes the mother able to conceive her own child as a mental subject, and to give him back, through interactions, this self- image as a subject endowed with a mind. The systematic lack of this capacity on the part of the caregiver, together with situations of discomfort and evolutionary risk, would lead to failure in the child's development of mentalization skills. With reflective function of the Self (Fonagy, [16]) or mentalization (Fonagy, [17]) we mean the intersubjective capacity to understand oneself and others, which becomes evident in the primary relationship between the child and the caregiver: to maintain the heart in mind and mind in heart "and" seeing oneself 
from outside and others from within" are expressions that capture this co- presence of cognitive and affective in an intersubjective perspective (Allen et al., Marchetti et al., [18]). In summary, the term mentalization includes both the cognitive component, already included in the ToM construct, and the emotional-affective component, which instead this construct doesn't contemplate, if not in some meanings that have proposed a distinction between a "hot" ToM and a "cold" (Brothers and Ring, [19]) or cognitive and affective (Shamay-Tsoory and Aharon-Peretz, [20]; Wang and $\mathrm{Su}$,$) , understood as the ability to reason respectively about non-$ epistemic mental states (emotions and desires) and epistemic (beliefs).

\section{Discussion}

To $\mathrm{M}$ researchers tried to establish at what age children achieved the ability to reason about behavior in metarepresentational terms. The beliefs, together with the desires, are in fact fundamental mental states for our actions in daily life, because the way in which we represent reality guides our choices and our behavior: «the mind represents the world and, to them once, such representations determine action (Wellman and Bartsch, [21]). As Doherty [22] specifies, there are three reasons that explain the centrality of understanding of beliefs for our social life: the predictability of behavior, which becomes not only understandable, but also predictable if we know what the other believes; the explanation of behavior, especially for those behaviors that, at first glance, seem strange or incomprehensible, the manipulation of behavior, since knowing the beliefs of the other allows us to intervene on them. In short: "if beliefs were always true, there would be no reason to consider them" (Doherty, [22]). From this focus on the mental state of belief emerges from the literature a consensus now unanimous about the centrality of the four- year evolutionary stage, an age in which most children in conditions of typical development overcome the false belief task, as evidenced by the meta-analysis of Wellman and colleagues [23]. The authors analyzed 77 articles published from 1983 to 1998, showing how 3-year and 5-month-olds report casual performance to false belief, while children aged 4 and more respond correctly in a statistically significant way. The age of four years is considered a sort of watershed between an developmental phase in which the child isn't yet able to reason at a meta-representational level about belief - so much as to commit what in the tasks of false belief is defined as "realistic error" (that is, to extend one's knowledge of reality to the other) - and a subsequent phase in which it achieves this ability that will allow it, in the following years, to articulate ever more complex levels of recursion of thought (second and third order recursive thinking).

Already in the first two years of life, children show that they possess cognitive structures and patterns that prepare the appearance of ToM, true precursors such as: social referencing (Sorce et al., [24]), joint attention, declarative pointing, the understanding of agency, the understanding of visual perception, the game of fiction. Shared attention and deictic gestures are fundamental stages of the communicative and linguistic development, constitutive "building blocks" of referential communication and the possibility of sharing the external world with the other. As Butterworth [25] has pointed out, the modulation of the visual orientation on the direction of the mother's gaze, together with the understanding and production of the gesture of indicating objects, constitutes the early foundation of referential communication. It is necessary to specify that the sharing of attention is a proto-communicative mechanism but doesn't yet presuppose a true ToM. It was Camaioni [26] who identified the value of ToM precursors in deictic gestures used with declarative function. In child-caregiver communication exchanges, consisting of dyadic sequences that leave room for triadic sequences (childcaregiver-object) starting from 6 months, deictic gestures initially perform an imperative or requested function. For example, the child indicates a distant object (pointing) or alternates the gaze between it and the adult (joint attention) so that the adult in turn looks at it, takes it and gives it to him: it is the performative demanded. Between 11 and 14 months there is a substantial change: the child always uses the gesture of pointing, but he does so also to take the adult's attention to something that is interesting to him, for the pleasure of sharing with a partner the interest in an element of reality (performative declarative). What changes, therefore, is the purpose of the deictic gesture, which is no longer used exclusively to act mechanically on the other, but to influence his mental state. We are always witnessing a manifestation of the mechanism of shared attention, but it is now underpinned by a new conception of the other: the child doesn't look at the adult only as an "agent of action", but as an "agent of contemplation", an individual with a mental world that can be influenced to share interests and intentions.

By agency we mean the understanding that animate beings act autonomously, in turn causing effects on other objects/ agents. This concept, in a very precocious and non-reflective form of representation within the first year of life (Gergely et al., [27]), constitutes the basis for the development of notions such as the distinction between being animated and inanimate, intention, the will, from which will stem the conception of the other as an autonomous being, whose behavior - expression of intentions - is motivated by mental states. Finally, as far as the game of fiction is concerned, the different elements present in it (substitution of objects, attribution to the object of imaginary properties, invention of non-existent objects) allow it to have a strong simulative value, which opens up the possibility of acting «as if », therefore the possibility of conceiving and manipulating a possible world next to the real world. For example, when the child plays "pretend" to call using a banana as a cell phone, he attributes a simulated property to the object and imagines another object not present, so he performs a decoupling operation between a representation and its real referent. The game of fiction has been counted among the psychological abilities most implicated in the development of the ability to understand the mind since the first systematic contributions on ToM (Astington et al., [28]). Through the analysis of the spontaneous language of children between two and four years observed in everyday life situations, Wellman and 
Bartsch [21] found that at the age of two, children explain people's behavior using the mental state of desire, while explanatory references to thoughts and beliefs appear later, around 3-4 years. These evidences led the authors to formulate the explanation of the conceptual change in the mentalistic understanding in preschool age, identifying an evolutionary sequence in which the child would pass from an early mentalism ( 2 years), in which the mental state of desire is the key to reading the own behavior and that of others (psychology of desire), to a later phase (3 years) in which (true) belief serves as a further lens with which to read the world (psychology of desire-belief), to finally arrive at the understanding of the false belief (About 4 years) as a subsequent explanatory tool for behaviors. Furthermore, alongside the definition of the development process of the various components of ToM in typical conditions, evidence was gathered about the presence of different levels within the same understanding capacity of the false belief; it would initially be understood at an implicit level, as shown by correct eye indicators but incorrect verbalizations (Clements and Perner, [29]: the child looks in the right direction, but provides the wrong verbal answer), and can also be understood at the non-verbal level, as shown by Call and Tomasello [30], Onishi and Baillargeon [31] and Surian and Geraci [32], who have placed the meta-representational understanding of behavior at an increasingly early age (15/17 months of life), giving rise to a heated debate (Perner and Ruffman, [33]). At the end of the nineties of the last century and the beginning of the 2000s the interest in the evolutionary path of ToM opened up to a life cycle perspective (Freeman, [34]; Khun, [35]), which considers development as a complex, multi- component and multi-factorial process. This path doesn't end with the achievement of the first adult age but is subject to continuous transformations also in the following adult age and in the old age (Lecce et al., [36]). The pioneer of this opening of the research on ToM from a life-span point of view was the work of Happé and colleagues [37]: using the Strange Stories (Happé, [38]), a complex task of ToM that evaluates the ability to understand and reason about stories with social content (eg. white lie, bluff, deceit, etc.) in a group of twentyyear-olds and in a group of seventy-year-olds, the authors pointed out that not only was ToM preserved in old age, but it was even better than young people.

However, this result was not replicated by the immediately subsequent research (German and Hehman, [39]; Maylor et al., [40]; Sullivan and Ruffman, [41]), which identified a deterioration in the performance of older people in classical tasks (such as the false belief task) and complex (such as the Strange Stories) due to advancing age. This discrepancy between the results of various researches was attributed to the high socio-cultural level of the sample chosen by Happé and colleagues [37], therefore not fully representative of the average elderly population. This lack of uniformity between the evidence of the first researches on ToM in physiological aging has become part of an increasingly fullfledged line of studies on ToM changes in the life cycle perspective, constituting one of the new frontiers of research in developmental psychology. This discrepancy between the results of various researches was attributed to the high socio-cultural level of the sample chosen by Happé and colleagues [37], therefore not fully representative of the average elderly population. This lack of uniformity between the evidence of the first researches on ToM in physiological aging has become part of an increasingly of studies on ToM changes in the life cycle perspective, constituting one of the new frontiers of research in developmental psychology. The impairment of Mind Theory is found in different clinical pictures through a wide range of behavioral anomalies. According to Baron-Cohen [42], one of the main characteristics of autism would be a sort of blindness to mental contents; an autistic individual seems to have deficits in perceiving of the existence of mental states in other people, and therefore seems unable to give a mentalistic explanation of the social interactions that surround him and involve him. The origin of the social and communicative difficulties of the autistic subjects would be to look for in a defective maturation of this cognitive mechanism. It is possible that in autistic subjects this maturation is compromised from the initial states or that it is reached with considerable delay. This would explain the symptomatic heterogeneity of the autistic syndrome, which includes both children completely isolated from the world, and individuals with significant intellectual capacity, such as subjects with Asperger's syndrome. Baron-Cohen, Leslie and Frith [3] showed that autistic children reported very poor results in rearranging vignettes that required understanding of belief, while they had no difficulty in sequencing stories about a character's desires or goals. Since this cognitive defect has been present since birth, it has been hypothesized that these children don't develop at all a Theory of Mind. At the basis of this disorder would be the failure of the develop of the meta- representational mechanism underlying the construction of a Theory of Mind. (Camaioni, [43]). A similar explanation has been proposed for schizophrenia. According to Frith [44] the schizophrenic patient would show similar alterations to those of autistic patients, due to ToM malfunction. Frith notes, however, that the development of subjects with schizophrenia appears completely normal until the first episode of psychic decompensation.

Thus, while the autistic person is an individual who has never reached the full capacity to reason about the mental states of other people, the schizophrenic would be an individual who has instead developed a substantially normal ToM in the course of his existence, but then lost, with the onset of the disease, the ability to use it correctly. This would happen due to the degeneration of particular neurons in the orbitofrontal cortex. Frith interprets delirium and hallucinations as the result of the attempt to give meaning to one's own and others' events and thoughts, after having lost the ability to represent them correctly and causally link them together. Some research (Wellman, Liu, [45]) support the idea that metacognition and ToM, in individuals with autism, are different abilities and highlight how these fail not so much in tasks that require an understanding of one's cognitive processes, but in those in which the understanding of epistemic mental states 
(such as the false belief of first and second order) and emotional states of others is required, which are types of understanding that come into play in social relations; therefore they solve the ToM tasks with difficulty (Peterson, Wellman, Liu, [46]). Scheeren et al. [47] examined advanced ToM in children and adolescents with HFASD (high-functioning autism) by administering a short collection of advanced social stories: these stories include a double bluff, violation of social rules, sarcasm, false belief and emotional understanding. Children and adolescents with HFASD seem to be able to infer the mental states of the protagonists of the story. Although this is incompatible with the theory of a generic ToM deficit in ASDs, children and adolescents with HFASD may however show limited ability to infer mental states during social interactions that occur in everyday life, as reported by the parents and by themselves. This study has shown that a different way of understanding the mind of others doesn't necessarily compromise its ability. However, in non-perfect circumstances (implicit social demands, time constraints, presence of so many stimuli), as happens in everyday social interactions, individuals with HFASD experience difficulties related to the understanding of others. Consequently, they seem to master the concept of ToM without mastering the ability to use it efficiently in their daily relationships. In explaining the deficits that characterize this pathology, ToM is conceived as an "all-or-nothing" phenomenon: either it is present, and it allows a normal functioning of psychic activities linked to the attribution of mental states, or it is absent, causing a series of difficulties in social interaction. Other authors (Semerari ,[48]) instead consider ToM as part of a wider mental activity: metacognition. This would include the ability to perform cognitive operations on one's own and others' mental states, but also that of using this knowledge for the solution of tasks or for mastering mental states that are the source of subjective suffering (Wells and Purdon, [49]).

The concept of metacognition would include both the theory of the mind and other mentalization skills. Authors of different theoretical orientations, from the psychodynamic one (Fonagy, [16]) to the cognitive one (Liotti [50]; Semerari, [48]), agree in assigning to metacognitive deficits a crucial role in the genesis of the symptomatology of serious disorders. People suffering from these pathologies often encounter serious difficulties, precisely in monitoring, differentiating, integrating and regulating their internal processes. For example, in avoidant, narcissistic and schizoid personality disorders there would be a difficulty in identifying and recognizing the different components of one's mental states, particularly with regard to emotions, desires and goals (Millon. [51]; Millon and Davis, [52]; Semerari, [48]). A metarapresentation deficit has been described in patients diagnosed with borderline personality disorder: in integrating different emotions and mental contents, these patients oscillate between representations of themselves and others of an opposite and contradictory nature (Liotti, [50]; Liotti and Intreccialagli, [53]; Semerari, [48]). It appears that common characteristics of serious personality disorders are attributable to alterations in metapensention and in emotional regulation, both expressing meta-cognitive functions. According to the current literature in clinical and developmental age psychology, many pathologies would be characterized by deficits of some metacognitive functions. These deficits would be found both in very serious pathologies such as autism and schizophrenia, where a more basic ToM deficit would be involved, both in less serious pathologies, in which the deficit would concern higher level metacognitive capacities. Functional neuroimaging studies and those conducted on brain lesions have helped to localize the brain circuits underlying the Theory of Mind. Studies on macaque monkeys have revealed that neurons in the central portion of the temporal lobe, particularly in the superior temporal sulcus (STS), light up selectively when monkeys observe the gaze direction of other monkeys. These neurons are activated even when the animals observe a direct action for a purpose (Gallese and Goldman, [8]). Functional imaging studies have revealed that the observation of movements of inanimate objects that seem to have a purpose (as opposed to random movements) in humans causes the activation of a homologous area of the temporal lobe. The same happens when the movement is implicit in the observation of a photograph (Kourtzi and Kanwisher, [54]). Thus, the activity of parts of the STS is linked to the observation of intentional movements. The temporal lobe also contains a particular type of neurons, called mirror neurons due to their unique quality of being activated both during the execution of a hand or mouth movement, and during the simple observation of the same movement performed by a 'other person. The discovery of mirror neurons in humans has offered an explanation of how the ability to imitate the actions of others can be evolved in the ability to simulate the mental states of others (Williams et al., [55]). However, as Frith and Frith [56,57] have emphasized, for the Theory of Mind it is not enough to represent actions directed to a purpose, but it is also necessary to know how to distinguish between behaviors generated by oneself or by others. The ability to simulate the mental states of others does not necessarily involve conscious reflection but can easily be brought back to a level of consciousness. The conscious reflection on one's own and others' mental states requires computational resources that go beyond the capacity to simulate or imitate an action and the structure assigned to this purpose is the inferior parietal cortex (IPC). And in particular the inferior right parietal cortex would seem to be important to consciously represent the mental states of others, while the inferior left parietal cortex could be involved in the representation of one's mental states (Decety and Chaminade, [58]). Recent fMRI studies show that ToM can be dissociated from other cognitive functions and that this performance is linked to a specialized socio-cognitive brain network, which includes the medial pre-frontal cortex and the cingulate cortex (MPFC), the posterior cingulate cortex (PCC) and the bilateral temporo-parietal regions (Gallagher and Frith, [59]; Saxe \& Powell, [60]).

Regarding the studies on children with ASD, Mostofsky et al., [61] found a weaker functional connectivity between the cerebellum and the motor areas during the execution of motor activity, while Khan et al., [62] found a weaker functional 
connectivity between the cerebellum and the areas associated with greater cognitive functioning (prefrontal, parietal and temporal) in children with ASD. The reduced cerebellar activation in these subjects could underline the role of the cerebellum in social cognition and suggest a deficit in the way the cerebellum is recruited in the social processing of children with ASD. Furthermore, it has emerged (Kana et al., [63]) that the neural nodes of the mentalization network (RTPJ, LTPJ and PCC) in the ASD are quite distant and therefore the connectivity could be weaker: on a biological level, this weakness can derive from abnormal trajectories of white matter in people with ASD, limiting the degree of synchronization, and this may be more evident when subjects with ASD are asked to perform tasks with high cognitive needs, such as ToM, processing of visual and linguistic information, memory of work and inhibition. Kobayashi et al. (2007) carried out a comparison between children aged between 8 and 12 years and adults with typical development: the results showed agerelated changes in the activation of bilateral temporo-parietal junction (TPJ) in false belief tasks, both verbal and non-verbal. With this they demonstrated the involvement of TPJ in the theory of mind during childhood. In children between 6 and 11 years, greater activation of the RTPJ (in addition to LTPJ and PCC) was observed when assessing the beliefs and opinions of others: this suggests a selectivity of these regions when evaluating the mental states of others (Saxe et al., [64]). Furthermore, this selectivity in the activation of RPTJ with respect to social facts increased with age (from 5 to 11 years) and was related to behavioral patterns of Theory of Mind (Saxe et al., [64]; Gweon et al., [65]). A different study, based on the use of electroencephalogram (EEG), with 4-year-old children, related RTPJ and MPFC to explicit and representational ToM (Sabbagh et al., [66]). In a more recent follow-up study, based on a sub- sample of children from the previous study, it was shown that the alpha EEG coherence in the $\mathrm{dmPFC}$ and in the skills implicated in the 4-year ToM predicts the development of a dmPFC selectivity in the tasks of the ToM at 7 - 8 years (Bowman et al., [6]). A further recent fMRI study has shown that the brain regions associated with physical pain and mental states are already functionally independent from the age of 3 and this functional independence increases with age and with the ability to perform tasks involved in Theory of Mind (Richardson et al., [67]). The most recent study on the neural correlates of ToM is from Xiao (2019), which found a common neural correlation pattern between different components of ToM: specifically, the analysis of the whole brain revealed a correlation of three components of the "Mentalizing network". A connection between RTPJ and PCC has been highlighted for both types of ToM (basic and advanced) and a connection between RTPJ and LTPJ for advanced ToM skills [68]. Although these ToM abilities emerge at different ages, no clear evidence of differences between their correlation patterns has been found [69]. Furthermore, significant positive correlations were found between an involvement of RTPJ in ToM abilities only within the socio-cognitive regions; while negative correlations have been highlighted outside the socio-cognitive network, that is IPL (inferior parietal lobe)/SPL (superior parietal lobe) and ITG (inferior temporal gyrus). These recent findings in young children offer new insights into the skills implicated in ToM in a developing brain, which may have implications for both typical and atypical childhood development in ToM [70].

\section{Conclusion}

To $\mathrm{M}$ is fundamental for social and relational life, as it allows us to understand and interpret our own and others' mental states: recognizing epistemic and emotional states of mind allows good social adaptation, especially if we can distinguish appearance from reality, to realize the existence of different emotions, desires and beliefs, to understand false beliefs, etc. (Cavalli, Sempio, Marchetti, [18]). Therefore, social behavior can be defined as based on a differentiation of mentalization skills; Lucariello et al. [71] distinguish a "social" and an "intrapersonal" ToM, which would develop separately: the "social" ToM, so called because it is used in social interactions, is the ability to understand mental states (including emotions) in others and is usually studied using the classic false belief tasks, instead the "intrapersonal" ToM, which is the basis of introspection, concerns the understanding of one's mental states and includes the ability to reflect, to maintain opposite representations of objects or events, and to learn (Cavalli, Sempio, Marchetti, [18]). Another author who believes that ToM influences more cognitive functioning rather than relation to social, emotional and relational functioning is Kuhn [35], who emphasizes the link between Theory of Mind and metacognition, not dealing with emotions and affects. In his theory, she places ToM at the base of metaconcept (which develops on three different dimensions: metacognitive, metastrategic and epistemological knowledge). In a life-span perspective, Kuhn [35] considers the development of meta- knowledge as "the conquest of a growing awareness, understanding and control of one's cognitive functions, as well as the awareness and understanding of these functions as they are present in others" [72]. Thanks to metaconcept, people can have control of their thoughts and their live, which is the same meaning that Flavell [73] attributes to the concept of metacognitive monitoring. Once again metacognition, ToM and emotions are connected, not allowing a clear differentiation between the three skills (Cavalli, Sempio, Marchetti, [18]). Metacognition is therefore understood as the ability of the individual to have a representation of own and others' mental states, to reflect on them and to use this information to effectively deal with problematic situations from an emotional, cognitive and behavioral point of view (Dimaggio et al., [74]). The metacognitive functions are analyzed, specifically, in the Interpersonal Metacognitive Therapy. This model of therapy responds to the need to find effective therapeutic tools for the treatment of patients with personality disorders. The metacognitive functions analyzed in the TMI are three, each of which includes specific sub-functions that act independently and at a growing degree of complexity [75].

The first function is the self-reflexivity that is the ability to think, understand and reason about one's mental states [76]. Basically it presupposes the acquisition of the ability to monitor, that is the identification of thoughts, beliefs and emotions, differentiation 
with respect to one's own convictions, that is, the ability to maintain a unified vision of oneself even if there is an alternation of different mental states. The second one is the understanding the mind of others, that is, the ability to understand the mental states of others [77]. It presupposes the ability to decentralize, that to empathize with others trying to make inferences about their mental states [78]. The third function is Mastery that is the modality that the patient puts in place to face situations in a conscious way, then use the knowledge at his disposal to decide, apply strategies and resolve interpersonal conflicts (Dimaggio et al., [79]). Interpersonal metacognitive therapy works by promoting the development of metacognitive functions, starting from the simplest ones that seem to be insufficient in therapy. Specific techniques are used aimed at the acquisition of a permanent metacognitive operation. This type of therapy could be a starting point to stimulate the acquisition of metacognitive functioning in patients with ASD, in order to improve their understanding of the mind of others and relational skills. In fact, those who present this type of pathology, relate to each other with difficulty and have a series of rigid expectations, which generate attitudes and emotional-behavioral reactions consistent with their predictions [80]. This relational circuit, therefore, confirms the person's own expectations and it maintains over time the conditions from which the activation of the dysfunctional interpersonal cycle originates, which also has a negative impact on the perception of the self [81]. Children with ASD often have difficulty building and maintaining social relationships, and this affects their relationship with the surrounding environment, the consequence of which is social isolation and low self-perception [82]. A study by McCauley et al. [83] compared a group of autistic children and a group of children with typical development to assess the perception of their selfesteem and examine how self-esteem is related to internalizing psychopathological disorders and theory of mind. The results showed that the self-esteem of boys with Autism Spectrum Disorder, measured with questionnaires such as SQD-II (Marsh [84]) and LSE (Harris et al. [85]), was found to be significantly lower than those in the control group. Furthermore, self-esteem was strongly correlated to depression in both groups but was negatively correlated to the theory of mind, assessed with two tasks, that of Strange Stories and the Silent Films Task (Davine and Hughes, [86]) only in the group of boys with ASD. Also as regards the neural correlates of self-esteem, an overlap was found between these and those implicated in Tom. In fact, using the fMRI technique, it has been shown that the right TPJ is also present among the areas involved in self-esteem, which is a fundamental area in the development of ToM [87]. A child's self-esteem depends on his thoughts, expectations and the relationship with the surrounding environment, and on his interactions. What emerges, therefore, is that ToM is a complex, multi-component construct, which involves different components: the life cycle perspective, neural circuits and links with abilities such as language, executive functions, decision-making, self-awareness processes [88]. Intervening by setting realistic expectations and staring concrete short-term goals can help the child with autism to enhance his self-esteem: the realistic goal to be achieved involves a confrontation with themselves, with the results achieved previously [89], in order to improve and achieve stronger self-esteem and increase chances of success. To achieve this goal, it is useful to program some changes in the environment, to facilitate the success in the required skills and to obtain satisfactory results.

\section{References}

1. Premack D, Woodruff G (1978) Does the chimpanzee have theory of mind? Behavioral and Brain Sciences 512-526.

2. Wimmer H, Perner J (1983) Beliefs about beliefs: Representation and constraining function of wrong beliefs in young children's understanding of deception. Cognition 13(1): 103-128.

3. Baron-Cohen S, Leslie AM, Frith U (1985) Does the autistic child have a theory of mind. Cognition 21(1): 37-46.

4. Perner J, Leekan SR, Wimmer H (1987) Three-year-olds' difficulty with falsebelief: the case for a conceptual deficit. British Journal of Developmental Psychology 5(2): 127-135.

5. Gopnik A, Wellman HM (1992) Why the child's theory of mind really is a theory. Mind and Language 7(1-2): 145-171.

6. Bowman LC, Liu D, Meltzoff AN, Wellman HM (2012) Neural correlates of belief- and desire-reasoning in 7- and 8-year-old children: an eventrelated potential study. Dev Sci 15(5): 618-632.

7. Bruner JS (1990) Acts of Meaning. Cambridge, MA: Harvard University Press. Tr It La ricerca del significato. Per una psicologia culturale Bollati Boringhieri.

8. Gallese V, Goldman A (1998) Mirror neurons and the simulation theory of mind-reading. Trends Cogn Sci 2(12): 493-501.

9. Meltzoff AN (2007) ‘Like me': a foundation for social cognition. Dev Sci 10(1): 126-134.

10. Jacob P, Jeannerod M (2005) The motor theory of social cognition: A critique. Trends Cogn Sci 9(1): 21-25.

11. Fadiga L, Fogassi L, Pavesi G, Rizzolatti G (1995) Motor facilitation during action observation: a magnetic stimulation study. Journal of Neurophysiology. J Neurophysiol 73(6): 2608-2611.

12. Leslie AM (1987) Pretense and representation: The origins of theory of mind. Psychological Review 94(4): 412-426.

13. Meins E (1997a) Security of attachment and maternal tutoring strategies: Interaction within the zone of proximal development. British ]ournal of Developmental Psychology 15: 129-144.

14. Meins E. (1997b) Security of attachment and the social development of cognition. Hove: Psychology Press.

15. Meins E, Fernyhough C, Russell J (1998) Security of Attachment as a predictor of symbolic and mentalising abilities: a longitudinal study.

16. Fonagy P (1991) Thinking about thinking: Some clinical and theoretical considerations in the treatment of a borderline patient. Int J Psychoanal 72(4): 639-656.

17. Fonagy P (1989) On tolerating mental states: theory of mind in borderline patients. Bulletin of the Anna Freud Centre 12(2): 91-115.

18. Cavalli G, Sempio OL, Marchetti A (2007) Theory of mind, metacognition, and emotions and affections: what links? Ricerca Psicoanalitica anno 18(3): 347-370.

19. Brothers L, Ring B (1992) A neuroethological framework for the representation of minds. J Cogn Neurosci 4(2): 107-18.

20. Shamay-Tsoory SG, Aharon-Peretz J (2007) Dissociable prefrontal networks for cognitive and affective theory of mind: a lesion study. 
Neuropsychologia 45(13): 3054-3067.

21. Wellman MH, Bartsch K (1994) Before belief: Children's Early Psychological Theory. American Psychological Association.

22. Doherty JM (2009) Theory of Mind: How Children Understand others' thoughts and feelings. Psychology Press. Clinical Psychology \& Psychoterapy.

23. Wellman HM, Cross D, Watson J (2001) Meta-analysis of theory-of-mind development: The truth about false belief. Child Dev 72(3): 655-684.

24. Sorce JF, Emde Robert NC, Joseph JK, Mary D (1985) Maternal emotional signaling: Its effect on the visual cliff behavior of 1-year-olds. American Psychological Association 21(1): 195-200.

25. Butterworth G (1991) The ontogeny and phylogeny of joint visual attention. In A Whiten (Edn) Natural theories of mind: Evolution, development and simulation of everyday mindreading 223-232.

26. Camaioni L, Longobardi E, Caselli MC, Volterra V (1993) Sviluppo gestuale e vocale nei primi due anni di vita. Psicologia Italiana 62-67.

27. Gergely G, Nádasdy Z, Csibra G, Bíró S (1995) Taking the intentional stance at 12 months of age. Cognition 56(2): 165-93.

28. Astington WJ, Gopnik A (1988) Children's Understanding of Representational Change and Its Relation to the Understanding of False Belief and the Appearance-Reality Distinction. Child Dev 59(1): 26-37.

29. Clements AW, Perner J (1994) Implicit understanding of belief. Cognitive Development 9(4): 377-395.

30. Call J, Tomasello M (1999) Does the chimpanzee have a theory of mind? 30 years later. Trends in Cognitive Sciences 12(5): 187-192.

31. Onishi KH, Baillargeon R (2005) Do 15-Month-Old Infants Understand Fals Beleifs. Science 308(5719): 255-258.

32. Surian L, Geraci A (2012) Where will the triangle look for it? Attributing false beliefs to a geometric shape at 17 months. The Br J Dev Psychol $30(1): 30-44$.

33. Perner J, Ruffman T (2005) Do infants really understand false belief? Response to Leslie. Trends Cogn Sci 9(10): 462-463.

34. Freeman NH (2000) Communication and representation: why mentalistic reasoning is a lifelong endeavour. Children's reasoning and the mind.

35. Kuhn D (2000) Theory of mind, metacognition and reasoning: a lifespan perspective. Children's reasoning and the mind 301-326.

36. Lecce S, Demicheli P, Zocchi, Palladino P (2015) The origins of children's metamemory: the role of theory of mind. J Exp Child Psychol 131: 56-72.

37. Happè FGE, Winner E, Brownell $H$ (1998) The getting of wisdom: theory of mind in old age. Dev Psychol 34(2):358-362.

38. Happé FGE (1994) An advanced test of theory of mind-understanding of story characters thoughts and feelings by able autistic, mentallyhandicapped, and normalchildren and adults. J Autism Dev Disord 24(2): 129-154.

39. German TP, Hehman JA (2006) Representational and executive selection resources in 'theory of mind': evidence from compromised belief-desire reasoning in old age. Cognition 101(1): 129-152.

40. Maylor EA, Moulson JM, Muncer A, Taylor LA (2002) Does performance on theory of mind tasks decline in old age? Br J Psychol 93(4): 465-485.

41. Sullivan S, Ruffman T (2004) Social understanding: How does it fare with advancing years? Br J Psychol 95(1): 1-18.

42. Baron-Cohen S (1995) Mindblindness: An essay on autism and theory of mind, Cambridge, Mass, Mit Press, trad it.

43. Camaioni L (1995) La teoria della mente Università Laterza-Psicologia,
Bari.

44. Frith CD, Corcoran R (1996) Exploring Theory of Mind in people with schizophrenia. Psychol Med 26(3): 521-530.

45. Wellman HM, Liu D (2004) Scaling of theory of mind tasks. Child Dev 75(2): 523-541.

46. Peterson CC, Wellman HM, Liu D (2005) Steps in theory-of-mind development for children with deafness or autism. Child Dev 76(2): 502-517.

47. Scheeren AM, Rosnay M, Koot HM, Begeer S (2012) Rethinking theory of mind in high-functioning autism spectrum disorder. J Child Psychol Psychiatry 54(6): 628-635.

48. Semerari A (1999) Psicoterapia cognitiva del paziente grave. Metacognizione e relazione terapeutica. Raffello Cortina Editore.

49. Wells A, Purdon CL (1999) Metacognition and Cognitive-Behaviour Therapy: A Special Issue. Clinical Psychology \& Psychotherapy 6(2): 71-72.

50. Liotti G (1999) Il nucleo del disturb borderline di personalità: un'ipotesi integrative. Psicoterapia.

51. Millon T (1991) Classification in psychopathology: rationale, alternatives, and standards. J Abnorm Psychol 100(3): 245-61.

52. Millon T, Davis RD (1996) An evolutionary theory of personality disorders. American Psychological Association 221-346.

53. Liotti G, Intreccialagli B (1998) Disorganized attachment, motivational systems and metacognitive monitoring in the treatment of a patient with borderline syndrome. American Psychological Association 356381.

54. Kourtzi Z, Kanwisher N (2000) Activation in Human MT/MST by Static Images with Implied Motion. J Cogn Neurosci 12(1): 48-55.

55. Williams JHG, Whiten A, Suddendorf T, Perrett DI (2001) Imitation, mirror neurons and autism. Neurosci Biobehav Rev 25(4): 287-295.

56. Frith CD, Frith U (1999) Interacting minds--a biological basis. Science 286(5445): 1692-1695.

57. Frith CD, Frith U (2001) The biological basis of social interaction. Science 10(5): 151-155.

58. Decety J, Chaminade T (2005) The Neurophysiology of imitation and intersubjeckivity.

59. Gallagher HL, Frith CD (2003) Functional imaging of 'Theory of Mind'. Trends Cogn Sci 7(2): 77-83.

60. Saxe R, Powell LJ (2006) It's the thought that counts: specific brain regions for one component of theory of mind. Psychol Sci 17(8): 692699.

61. Mostofsky SH, Powell SK, Simmonds DJ, Goldberg MC, Caffo B, et al., (2009) Decreased connectivity and cerebellar activity in autism during motor task performance. Brain 132(9): 2413-2425.

62. Khan AJ, Nair A, Keown CL, Datko MC, Lincoln AJ, et al. (2015) Cerebrocerebellar resting-state functional connectivity in children and adolescents with autism spectrum disorder. Biol Psychiatry 78(9): 625-634.

63. Kana J, Jose O Maximo, Diane L Williams, Timothy A Keller, Sarah E Schipul, et al. (2015), Aberrant functioning of the theory-of-mind network in children and adolescents with autism. Springer 6(1).

64. Saxe R, Whitfield-Gabrieli S, Scholz J, Pelphrey K A (2009) Brain regions for perceiving and reasoning about other people in schoolaged children. Child Dev 80(4): 1197-1209.

65. Gweon D, Feder D, Bedny M, Saxe R (2013) Theory of mind performance in children correlates with functional specialization of a brain region 
for thinking about thoughts. Child Dev 83(6):1853-1868.

66. Sabbagh MA, Lindsay C Bowman, LE Evraire, Jennie MB (2009) Neurodevelopmental Correlates of Theory of Mind in Preschool Children. Child Dev 80(4): 1147-1162.

67. Richardson H, G Lisandrelli, A Riobueno-Naylor, R Saxe (2018) Development of the social brain from age three to twelve years. Nat Commun 9(1).

68. Baron-Cohen S (1995) "Mindblindness: An Essay on Autism and Theory of Mind".

69. Bosco FM, Colle L, Pecorara RS, Tirassa M (2006) ThOMAS, Theory Of Mind Assessment Scale: Uno strumento per la valutazione della teoria della mente.

70. Bruner JS (1986) Actual minds, possible worlds, Cambridge, Mass., Harvard University Press; trad.it. La mente a più dimensioni.

71. Lucariello J, Le Donne M, Durand T, Yarnell L (2006) Social and intrapersonal theories of mind."I Interact Therefore I Am”. Springer.

72. Camaioni L (2001) La teoria della mente nello sviluppo tipico e atipico.

73. Flavell JH (1979) Metacognition and cognitive monitoring: A new area of cognitive-developmental inquiry. American Psychologist 34(10): 906-911.

74. Antonio Semerari, Antonino Carcione, Giancarlo Dimaggio, Maurizio Falcone, Giuseppe Nicolò, et al. (2003) How to evaluate metacognitive functioning in psychotherapy? The metacognition assessment scale and its applications. 10(4): 238-261.

75. Caravita S, Milani L, Traficante D (2018) Psicologia dello sviluppo e dell'educazione, Mulino.

76. Chaminade T, Meltzoff AN, Decety J (2005) An fMRI study of imitation: action representation and body schema. Neuropsychologia 43(1): 115127.

77. Fonagy P, Target M (1996) Playing whit reality: I. Theory of mind and the normal development of psychic reality. Int J Psychoanal 77(2): 21733.

78. Frith CD (1992) The Cognitive Neuropsychology of Schizophrenia. Psychology Press.
79. Dimaggio G, Montano A, Popolo R, Salvatore G (2013) Terapia metacognitiva interpersonale. Raffello Cortina, Milano.

80. Gopnik A, Aslington JW (1988) Children's understanding of representational change and its relation to the understanding of false belief and the appearance-reality distinction. Child Dev 59(1): 26-37.

81. Gopnik A, Meltzoff AN (1997) Words, thoughts, and theories. Cambridge, MA: Mit Press.

82. Kobayashi C, Glover GH, Temple E (2007) Children's and adults' neural bases of verbal and nonverbal 'Theory of Mind'. Neuropsychologia 45(7): 1522-1532.

83. McCauley JB, Harris AM, ZaJic M, Lerro SEL, Oswald T, et al. (2017) SelfEsteem, Internalizing Symptoms, and Theory of Mind in Youth with Autism Spectrum Disorder. J Clin Child Adolesc Psychol 48(3): 400-411.

84. Marsh HW (1992) SDQ II: Manual. Sydney, Australia: Self Research Centre, University of Western Sydney.

85. Harris A, Brimblecombe N, Knapp M, Murguia S, Mbeah-Bankas H, et al. (2017), The role of youth mental health services in the treatment of young people with serious mental illness: 2-year outcomes and economic implications. Early Interv Psychiatry 11(5): 393-400.

86. Devine RT, Hughes C (2013) Silent films and strange stories: theory of mind, gender, and social experiences in middle childhood. Child Dev 84(3): 989-1003.

87. Perner J, Wimmer $\mathrm{H}$ (1985) John thinks that Mary thinks that... Attribution of second order beliefs by 5-to 10-year-old children. Experimental Child Psychology 39(3): 437-471.

88. Wang Y, Su Y (2006) Theory of mind in old adults: The performance on Happe's stories and faux pas stories. Psychologia.

89. Xiao T, Fang H, Wu Q Li Y, Ren Y, et al. (2019), Structural networks in children with autism spectrum disorder with regression: A graph theory study. Behav Brain Res 378: 112262.

\section{Your next submission with Juniper Publishers will reach you the below assets}

- Quality Editorial service

- Swift Peer Review

- Reprints availability

- E-prints Service

- Manuscript Podcast for convenient understanding

- Global attainment for your research

- Manuscript accessibility in different formats

( Pdf, E-pub, Full Text, Audio)

- Unceasing customer service

Track the below URL for one-step submission

https://juniperpublishers.com/online-submission.php 